\title{
Fuel Type Classification in the Mediterranean Basin Context: State of the Art and Future Research
}

\author{
Duka Isida and Ioannilli Maria
}

\begin{abstract}
Knowledge of fuel distribution and its characteristics are essential for fire models and fire management system especially in the Mediterranean Basin where fires are an essential environmental task. Several fuel type classifications have been developed worldwide. Each of them fit the specific vegetation characteristics and the adopted fire model for the specific country. Efforts to develop a unique fuel schema in the Mediterranean Basin shown that is quite complex because of the structural heterogeneity and complexity of the plant community. So a well based methodology to describe and map fuel in Mediterranean is needed. A first application of the methodology will be Italy. It will be based on a pattern approach at regional and local scale, obtained by different data cross. Earth observation data, in particular radar and infrared, will be used to build up index. Further research will be conducted.
\end{abstract}

Index Terms-Forest fire, fuel models, fuel type classification system.

\section{INTRODUCTION}

\section{A. Forest Fire Phenomenon, Its Parameters and Variables}

It is known that a fire occurs when three elements, heat, fuel and oxygen (the so called "Fire triangle, shown in Fig. 1) are present and combined in the right mixture and can be extinguish by removing one of these elements [1].

Four groups of forest fires are distinguished [1].

1) Surface fires. In this case fires burn the fuelbed and grassland without penetrate in soil cause of its moisture.

2) Crown fires. These types of fires are typical of resinous forest. Fires burn the crown of the trees and, helped by wind, spread rapidly from a crown to another.

3) Ground fires, which occur mostly on drought periods burning the organic material of forests.

4) Log fires. These types of fires occur in chestnut forests and olives especially those abandoned by human.

Forest fires are a fascinating phenomenon as well as complex, affected from multiplies interactive variables. Their study involves a lot of disciplines e.g., ecology, earth observation and environment monitoring. Considering the phenomenon complexity, to better understand and prevent the event, we will divide it in three interactive components: 1) Causing, 2) Spread factors, and 3) Impacts. These

Manuscript received June 28, 2015; revised August 31, 2015. This work was supported by the University of Rome 'Tor Vergata', in the framework of the $\mathrm{PhD}$ in Computer science, Control and Geoinformation. Academic year 2014-2015.

The authors are with University of Rome 'Tor Vergata', Department of Civil Engineering and Computer Engineering, Rome, Italy (e-mail: duka@ing.uniroma2.it, ioannilli@ing.uniroma2.it). components and their interaction are described in Fig. 2. While the first component is well known by the literature, the third one is rarely mentioned, due the complexity in its estimating. Impact factors can be of three categories: a) ecosystem, b) economic and c) social.

1) Ecosystem forest fires impacts can be both positive and negative [2]. Forest fires are environmentally necessary. In one hand, if they are checked, their passage stimulate reproduction of a species (e.g., Cistus, Halimium, etc.) but in the other hand, if they are frequent in an area and uncontrolled, they could became dangerous and bring to completely destruction, lose or behavior variation of other species [2]. The first negative impact after fire passage is environment deterioration, easily recognizable from losing of leaf and trees crown and trunk destruction. This visual (direct) impact does not mean a loose of biodiversity.

2) Economic impacts of fire are direct impacts and they can be evaluated in terms of costs. Costs are normally referred e.g., to restoration of ecological corridors, rehabilitation of erosion soil, etc.

3) Social impacts are rarely mentioned in bibliography, because they are not easily predictable. They are indirect impacts and it is quite difficult to estimate such impacts in terms of costs. They mainly related to the landscape damage and, secondly, to human health impacts caused by toxic gases produced by fire, in particular $\mathrm{CO}_{2}{ }^{1}$.

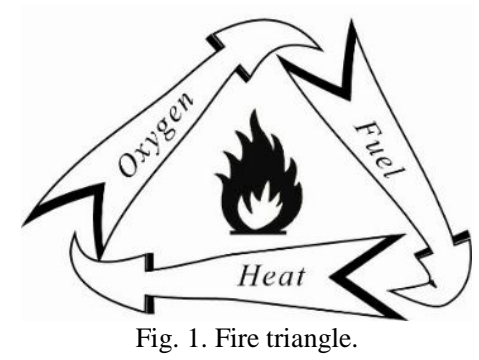

Talking about the second component of the phenomenon, the spread factors, homogeneous and well known methodologies are formulated in literature, and assumed worldwide, for: terrain orography, hydrology and weather condition; specific criticisms still remain concerning to the fuel flammable properties. The existing methodologies, outlined to study the variable, are heterogeneous and inappropriate to be used in other contexts from those in which they were developed, because they have been designed, in each country, to better fit the own specific vegetation characteristics.

\footnotetext{
${ }^{1}$ The effects of $\mathrm{CO}_{2}$ and other gases produced by fire on human health are under study.
} 


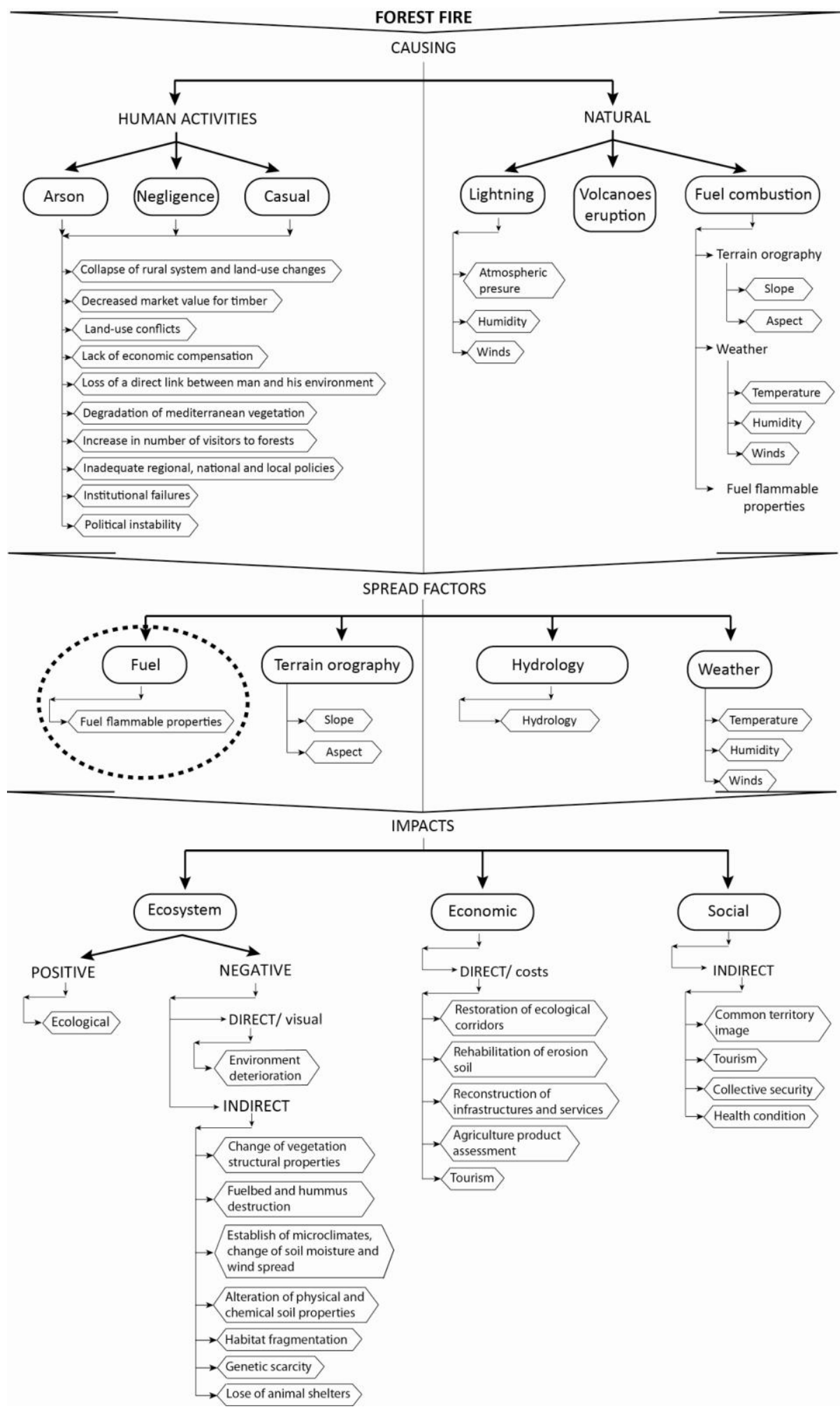

Fig. 2. Forest fire phenomenon, its parameters and variables based on the study of the spread factors. Among all the factors, the flammability properties of forest species, conventionally named fuel model, represent a very critical element, since they are closely related to the local characteristics of forest fuels. An inappropriate fuel model can therefore affect the significance of a fire model.

In order to understand, describe e predict the forest fire phenomenon, specific fire models have been developed,

The availability of suitable fuel models representing the actual characteristics of forest fuels proper to a given context, constitutes the key element for a good forest file model.

Thus, the first step of the proposed research activity, concerning the study of forest fire in the Mediterranean basin, focuses on the definition of a new fuel model, useful to account the flammability of the specific forest species located in that context.

\section{TOOLS TO PREDICT Forest Fire EventS}

\section{A. Terminology}

Imprecise use of certain terms regarding forest fuels often causes confusion and misunderstanding. It is worthwhile to briefly review the main ones. It is known that fire behavior is influenced by fuel, topography and weather condition. Fuels are defined in terms of physical characteristics of the live, dead and canopy biomass that contribute to the spread, 
intensity and severity of fire [3]. The life and dead surface is known as ground fuel (fuelbed) and it lies on the ground floor of the forest [4]. It is made of duff, freshly tree leaves, grass, low shrubs, dead tree branches and down logs whereas the canopy it is known as the aerial fuel. The canopy is made by trunks, limbs, leaves, hanging moss and standing snags.

In order to describe in a synthetic way the physical characteristics for all fuels in an area, various classification schemes are normally used, which summarize large groups of vegetation into different classes. These groups are usually called fuel types [5]. Fuel types are determined as "association of fuel elements of distinctive species, form, size, arrangement, and continuity that will exhibit characteristic fire behavior under defined burning conditions" [6]. To describe the potential characteristics of a fire through mathematic relationship we use fire models [5].

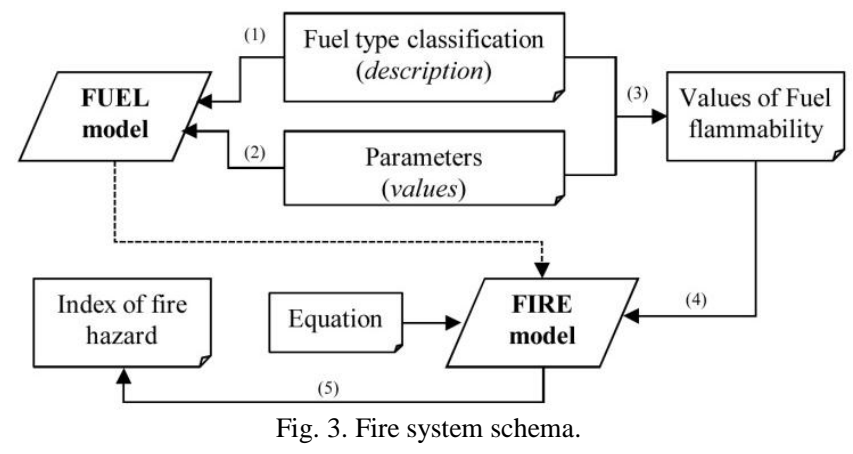

Informally fire models are referred as fire behavior or fire effects models [5]. Fire models are driven in input by a set of parameters, which are fuel models.

In conclusion, as shown in Fig. 3, fuel models are a set of number which describes the flammability properties of each fuel type whereas fire models are equation that describes fire behavior according to the characteristic of fuel type [5].

\section{B. Evolution of Fuel Models Worldwide}

A lot of fire models and fuel classification system have been developed worldwide. The pioneering efforts to determine models that can predict fire hazard began in the western United States of America (USA) during the period 1910 -1920 [7]. After that, the US Forest Service realized that science-based strategy would be needed to both explain and predict fire activity in the western USA [7].

The first fire - danger-meter was built in 1931 by Harry T. Gisborne [7]. This tool became very popular and was implemented in many regions in USA at that time. The Gisborn's core idea evolved in time to better fit all the specific region's needs, until 1960.

Approximately ten years after, in 1972, was developed the National Fire-Danger-Rating-System (NFDRS) from the Rothermel's fire spread model [7]. Rothermel introduces, for the first time, a set of inputs for his mathematical fire spread model, defining eleven fuel models [8]. In 1976, Albini added two others fuel models to the eleven Rothermel's models [9]. This set of fuel models became the original thirteen fuel models in USA.

In 1982, Anderson produced a new update to the Albini fuel models and provided help on selection of a proper fuel model. In 2005, Scott and Burgan introduced new forty-three fire behavior fuel models, which differ from the original Albini's models. However, all these models are applicable to fire behavior modeling system, which use Rothermel's surface fire spread model.

To describe fire behavior and fuel characteristics across United States, theoretical fire and fuel models have been integrated in software tools (e.g., BEHAVE, FARSITE, FOFEM, BluSky, SMOKETRACKS, Fire Effects Tradeoff, etc).

Canada and Australia made efforts in order to describe the specific vegetation characteristics in relation of fire hazard. The principal system used to estimate fire hazard in Canada is the Canadian Forest Fire Danger rating System (CFFRDS), which is composed of two major subsystem: the Canadian Forest Fire Weather Index System (FWI) and the Canadian Fire Behavior Prediction System (FBP), both introduced by Van Wagner in 1984 [10].

The Canadian fuel classification system is organized into five groups(coniferous, deciduous, mixed wood, slash and open) and 16 discrete fuel types [10]. The CFFDRS system leads Canada to be recognized as a leader in fire science and fire management expertise. Because of its simplicity, adaptation and support of a variety of situation, the system has been implemented in some part of USA and in New Zealand. Moreover, some model's components have been implemented in many countries such as Spain, Portugal, Sweden, Argentina, Mexico, Fiji, Indonesia and Malaysia.

In Australia, in 1960s, McArtur designed the fire danger meter system, based on the meter used in USA in 1950s. McArthur developed two meters for estimate fire danger, based on two fuel types: the Forest Fire Danger Meter (FFDM) and the Grassland Fire Danger Meter (GFDM). The Forest Fire Danger Meter is expressed through an index, from low (0) to extreme (100) [11] which is related to the chance of fire to start and spread, to its intensity and difficulty to suppression. The index takes into account three variables: air temperature, wind speed and relative humidity. Both Fire models were developed by correlating fire behavior from experimental fires and observation of wildfires with fuel and weather parameters [5]; they are used for all type of forest in Australia. Now-days in Australia the Canadian Forest Fire Weather System (FWI)is used, which is rather adaptable to investigate how weather influence fire behavior day-to-day [12].

Europe and in particular the Mediterranean Basin does not have own fire models and a unique fuel classification system. Fire models used in the Basin are taken from those developed for America and Canada, whereas their fuel classification systems cannot be adapt because they do not fit the Mediterranean vegetation characteristics. Efforts to determine a unique fuel classification system for the Mediterranean Basin began lately in 1999 with Prometheus project. In this context, a classification system was produced, based on the principles of the Northern Forest Fire Laboratory (NFFL) developed in 1976 by Albini. It comprises seven fuel types, based on height and density of the fuel, two characteristics which influence directly the intensity and propagation of wildfire [13]. However, this system did not describe all the fuel types of the Basin. Therefore, countries of the Mediterranean Basin have produced their own, local or regional, fuel classification system without a standardized 
methodology.

In 2011, under ArcFUEL project ${ }^{2}$ was determined a fuel classification system composed by forty-two fuel types. The project results were applied and validated in four Mediterranean countries: Greece, Portugal, Spain and two major region of Italy (Calabria and Sardinia). [14]:

The ArcFUEL methodology is based on the following step

1) definition of a fuel map classification scheme,

2) use of existing datasets for mapping the main forest fuel classes,

3) use of multi-temporal LANDSAT Thematic Mapper (TM) images for the distinction of fuel classes with different seasonal characteristics,

4) refinement of the produced fuel classes based on canopy cover density data,

5) merging of all produced map layer in a single layer,

6) further sub-classification of the produced maps based on the ECOREGIONS data.

The input data used to determine the forty-two fuel type classifications are described in Table I.

Now-day ArcFUEL classification seems to be the anchor system for the Mediterranean Basin however, it shows some relevant issues that need to be addressed further in the future research activity in order to improve the effectiveness of fire prevention and management activities.

TABLE I: ARCFUEL INPUT DATA

\begin{tabular}{cccl}
\hline \hline Source & Name & $\begin{array}{c}\text { Spatial } \\
\text { resolution }\end{array}$ & \multicolumn{1}{c}{ Information } \\
\hline JRC & $\begin{array}{c}\text { Forest type map } \\
2006\end{array}$ & $25 \mathrm{~m}$ & $\begin{array}{l}\text { Maps Broadleaved and } \\
\text { Coniferous forests in } \\
\text { Europe }\end{array}$ \\
\hline JRC & Ecoregions & $250 \mathrm{~m}$ & $\begin{array}{l}\text { Maps different } \\
\text { Ecoregions in Europe }\end{array}$ \\
\hline JRC & FuelMap & $250 \mathrm{~m}$ & Maps Fuel in Europe \\
\hline JRC & Forest Cover & $250 \mathrm{~m}$ & $\begin{array}{l}\text { Canopy forest cover in } \\
\text { Europe }\end{array}$ \\
\hline JRC & Burned area & $1 \mathrm{ha}$ & $\begin{array}{l}\text { Maps produced each } \\
\text { year depicting burned } \\
\text { areas greater than 1ha }\end{array}$ \\
\hline EEA & maps & $100 \mathrm{~m}$ & $\begin{array}{l}\text { Land cover map of } \\
\text { Europe }\end{array}$ \\
\hline USGS & Landsat TM & $30 \mathrm{~m}$ & $\begin{array}{l}\text { Remotely sensed } \\
\text { imagery }\end{array}$ \\
\hline METI & ASTER GDEM & $30 \mathrm{~m}$ & $\begin{array}{l}\text { Digital Elevation } \\
\text { Model of the World }\end{array}$ \\
\hline \hline
\end{tabular}

\section{METHODOLOGY}

\section{A. The Mediterranean Basin Context}

Fires are common events in the Mediterranean Basin. Statistics show that $94 \%$ of forest fires in the Mediterranean Basin are caused by human activity [15]; however, the near future expected climate change in the Mediterranean Basin, included a rise in temperature, more drought and severe storms[16], could increase the probability of forest fire events.

\footnotetext{
${ }^{2}$ ArcFUEL project was promoted by the European Commission through LIFE+, to deliver a standardized methodology for the Mediterranean Basin using the existing data and to develop forest fuel map for it.
}

The Mediterranean Basin is a closed basin, located on the western side of a large continental area and connected to the Atlantic Ocean through the narrow Gibraltar Strait [17]. It is extend with an approximately surface of 2 million $\mathrm{km}^{2}$ [18] at the intersection of two major landmasses, Eurasia and Africa. It is thus nearly ten times greater in size than any other Mediterranean type-ecosystem ${ }^{3}$. This space represent not only one of the most important and complex region in terms of biodiversity, which can be understanding by its geographic location, but even a great mosaic of culture and society that influence each other [19].The major part of Mediterranean Basin physiography was created during the Tertiary and extended into the Quaternary, with the subsistence and uplift of the Alps [20]. As result, the landscapes of the Mediterranean Basin vary according with its great topographic and climatic heterogeneity. Another historic event linked to the importance of understanding the patterns of diversity in Mediterranean Basin is associated to the climatic oscillations that occurred since the Miocene-Pliocene, the period from which is dated the establishment of a Mediterranean type climate [21]. The Basin lies in a transition zone between the arid climate of North Africa and the rainy climate of central Europe, and it is affected by interaction between mid-latitude and tropical process which determine a mild and wet winter and a hot summer [16]. References [16]-[22] show that the current climate change trend in Mediterranean Basin is provoking longer summer droughts and intensification of them even out of season, identifying the Basin as one of the most prominent "Hot-Spots" in future climate change [16].

Reference [21] shows that a set of factors, such climate, geomorphology, pedology, hydrology and especially land-use practice, had determinate, in the Mediterranean Basin ecosystem, an extremely high diversity of vegetation types and communities. The Mediterranean Basin represents one of the most important regions in the world for its biodiversity feature. The current flora of the Mediterranean Basin is a mix of taxa with various biographic origins, ages and evolution history, including approximately 25000 species of flowering plants and ferns and more than half of them are endemic plants [21].

They represent $10 \%$ of the world's flowering plants on just over $1.6 \%$ of the Earth's surface and host a great faunal diversity too [22]. Their evolution began in Pliocene under tropical climatic condition and some of them disappeared during the glaciations period [21]. The principal vegetation association of the Mediterranean Basin ecosystem is maquis ${ }^{4}$. The now days Mediterranean Basin landscape surface is covered, at least $35 \%$, by woodlands and most of this areas are constitute by deciduous woodlands [23] although the dominant species are the evergreen oak (e.g., Quercus ilex., $Q$. calliprinos). Because of a long time of human influence in the

\footnotetext{
${ }^{3}$ Mediterranean- type ecosystems (MTEs) occur in areas characterized by winter rainfall and summer drought. Five region of the world are recognized as possessing MTEs namely: Mediterranean Basin, California, central Chile, the southern and southwestern Cape Province of South Africa, and southwestern and parts of southern Australia [20].

${ }^{4}$ Maquisis the European term to define the association of vegetation shaped by the Mediterranean climate. In California, it is known as chaparral, in Spain matorral and in Italy macchia.
} 
area, many of the forest have been replaced with scrublands, dominated by species of Juniperus, Phillyrea and Pistacia.

The now day vegetation of the Mediterranean Basin is a result of anthropogenic fires, and it is called by many ecologists fire-climax [23]. Human starts to use fire in this region during Neolithic, about 10000 years ago, intentionally destroying forests for agriculture and pasture [21]. In the Mediterranean, forest fires contributed to the structure and function of ecosystems.

As stated above, forest fires could be environmentally necessary, due the capacity of fire passage to stimulate the reproduction of many species; so, if forest fires are an integral part of the Mediterranean Basin and if they are environmentally necessary, why is it important to study the phenomenon and prevent the event?

In the last years forest fires have heavily affected the Mediterranean Basin. Every year more than 50000 fires burn an average of $1.3-1.7 \%$ forests in the Mediterranean Basin [15]. The burned areas have enormously increased starting from 60s in countries like Italy, Spain, Greece and Portugal. Many authors [15] state that phenomenon seems to be connected, in these countries, with economic and urban development, and outline as the capacity of ecosystems to self-regeneration has then been reduced.

From this specific point of view, it is therefore important to prevent the events: to do this a crucial element is the availability of fire models useful to assess the potential behavior of forest fires and to support decision-making for fire suppression.

\section{B. Technical Approach}

The research that is being conducted at this time has the objective of producing a new fuel classification scheme, which will be tested within the Italian context. Italy represents one of the most variety countries in terms of vegetation cover determined primary by its climate. Its territory is extend in the middle of the Mediterranean Basin in two bioclimatic zones namely Temperate zone (Alps, Apennine and Padania) and Mediterranean Zone (Sardinia, Sicilia, Coastal West Italian and Apulia), and six bioclimatic regions [24].

The conventional limit between the two zones, along the watershed is nuanced, especially on the Adriatic coast. From the vegetation point of view, six main areas (bands) are recognized in Italy. Some bands are present in both climatic zones, others in only one of them. It also happens that some formations, belonging to a certain band, appear to the outside of it, as part of another band.

Moreover, from the orographic point of view, Italy is composed of five different areas: coastal and inland mountain, coastal and inland hills and flat land.

In this context it is possible that a same vegetation type (e.g., the evergreen oak forests) presents different characteristics, relevant for the flammability properties, depending on climate zone, vegetation band and specific terrain orography.

Currently the most common used systems to estimate fuel flammability in Italy are taken from Abruzzo and Sicilia case studies. They estimate the potential of fuel for fire hazard based on their forest attribute and combining it with Fire Behavior models and Fire hazard index. But, as above discussed, each fuel type classification is only applicable for similar geographic locations, and it cannot be correctly used for other environments; then the results arising from the application in other Regions of these systems are quite unsatisfactory. Furthermore the current studies do not adopt a national recognized methodology.

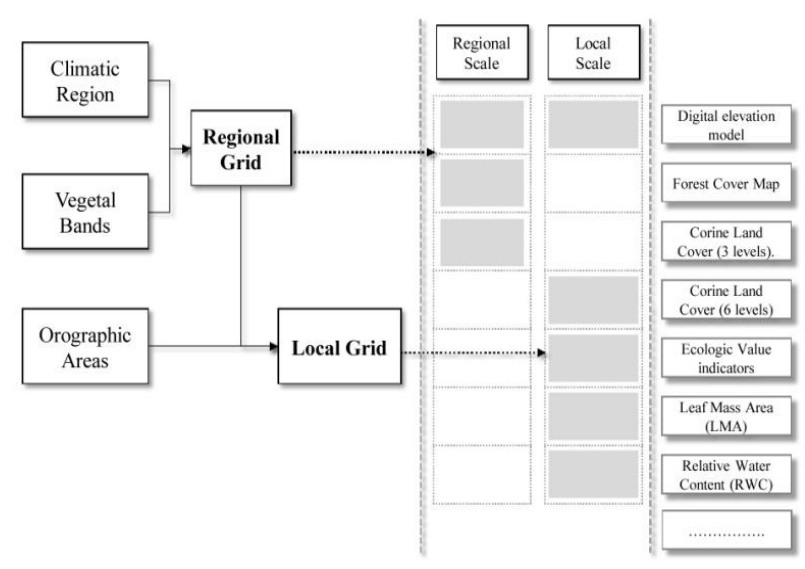

Fig. 4. The conceptual schema for the analysis.

So it is important to define an appropriate methodology to map Italian fuels and define a national fuel type classification system.

A first approach to describe and map Italian fuels, as shown in Fig. 4, will be based on the definition of two different partitions of the national territory, which will realize the spatial grids to be used to specialize the properties of each vegetal pattern, in term of flammability at different scale: regional and local scale.

This double scale approach may fit better the Italian needs for the following reasons.

1) Vegetal associations are different. Sometimes they are homogeneous, made only by species which show the same characteristics and flammability properties. Others, too complex to be described under a unique class of flammability. A typical case, from this point of view, is the maquis that, although primarily consists of the same plant species, is much diversified in space and in terms of flammability, depending on the vegetal pattern and association, the special climatic and orographic conditions, the anthropogenic component of the landscape. In this context vast fuel classes can be used to describe vegetation at regional to implement models which describe fire behavior for the "Regional Plan of prevision, prevention and fight against forest fires". Investigate flammability of vegetal species related to each other (vegetal structure) through pattern approach is however indispensable because in Italy, in most cases, we do not have homogeneous forest but vegetal association. So it will be improper to investigate flammability of a single species.

2) Available data are in different scale and details.

3) Fuel types identified at a local scale will be more specific and will be used in dynamic models.

\section{DISCUSSION AND CONCLUSION}

Knowledge of fuel distribution and its characteristics are 
essential for fire models and fire management system. Several fuel classification systems have been developed worldwide since 1916. Each of them fit the local vegetation characteristics and fire models for which they were developed. So it is important to select, for each place, the appropriate fuel model which better describe fire behavior. The large structural heterogeneity and complexity of the plant community in the Mediterranean Basin, makes the definition of an appropriate fuel schema quite complex. The recent efforts to determine a unique fuel classification schema for the Mediterranean Basin, under ArcFUEL project, show that relevant issues that need to be addressed still remain, in order to improve the effectiveness of fire prevention and management. The ArcFUEL adopts a forty-two fuel types classification schema, but such schema presents two major problems.

1) The proposed classification groups fuels with same structural and vegetation characteristics but not consider their fire properties. For example, into the fuel nr.20 named Mediterranean long needled conifer forest (Mediterranean pines) are included all the conifers without considering that each conifer group could present specific fire property (e.g., fuel heat, extinction moisture, etc.) depending on its characteristics and location. It is well known that the Mediterranean basin represents one of the most important regions in the world for its biodiversity, and that its vegetation is a mix of various taxa, too complex to be described through a unique fuel group. Furthermore, the vegetation of each country of the Basin, and in many cases each specific site inside county, has the own specificity, related to the climate, morphology, soil properties and landscape structure. So it is improper to define and use a unique fuel type classification system for all the Mediterranean Basin countries.

2) The proposed classification is highly affected by the needs to obtain a fuel map geo data base, homogenous at European level. This means that the adopted methodology, in defining the classification schema, results as a compromise between the need of having accurate information and the possibility of getting such information at the desired scale at reasonable cost. In fact, the production of a fuel map is based on a very synthetic classification systems, and it is also largely dependent from the final required map scale. Talking about scale, and referring to Kean [25], only the coarse (national) scale (which provides a rough description of the spatial distribution of landscape unit) can be addressed by using the ArcFUEL classification schema. At mid-local and fine scale more complex classification schemes are required, that do not oversimplify the description of wildly and fuel beds and contain information on the vegetation structure.

However the ArcFUEL classification schema can represent a good start to develop a further and more detailed fuel type classification based on vegetation flammability properties in order to define more appropriate fuel models at mid-local scale.

Taking in consideration the ArcFUEL methodology to map fuel types in the Mediterranean Basin, a first assumption of the input data will be the following.

1) Corine Land Cover (CLC). In relation of the considered scale (regional or local) it is planned to use this source of data at different level of classification, starting from the aggregate one (three classes) the maximum available level of classification (e.g. the one produced by the Lazio Regional Parks Agency which details the land cover legend into 6 level).

2) Forest Cover map.

3) Ecologic Value indicator, defined by the Institute for the Environment Research and Protection known as ISPRA. This indicator describes the spatial distribution of Habitat and will be used in absence of the Habitat map.

4) Previously burned area maps.

5) Digital Elevation Map (DEM).

The mentioned data, but not limiting to them, will be integrated with other index e.g., Leaf Mass Area (LMA), Relative Water Content (RWC), soil moisture etc., which investigate the flammability properties of fuels. To build up the indexes is planned the use of earth observation data, particularly radar and infrared. Further research on this specific direction will be done.

\section{REFERENCES}

[1] S. Landi, Organizzazione Tecnica Della Lotta Contro Gli Incendi Boschivi, Roma: Laurus Robuffo, p. 43, 1994.

[2] M. D. Lillis, "Ecologia del fuoco," in Ecologia Vegetale, S. Pignatti, Ed., Torino: UTET, ch. 17, pp. 297-313, 1995.

[3] R. E. Keane and M. Reeves, "Use of expert knowledge to develop fuel maps for wildland fire management," Expert Knowledge and Its Application in Landscape Ecology, New York Dordrecht Heidelberg London: Springer, ch. 11, pp. 211-228, 2012.

[4] J. S. Barrows, "Natural phenomena exhibited by forest fires," in International Symposium on the Use of Models in Fire Research, W. G. Bert, Ed., Washington: National Academy of Sciences, National Research Council, pp. 281-288, 1961.

[5] L. A. Arroyo, C. Pascual, and J. A. Manzanera, "Fire models and methods to map fuel types: The role of remote sensing," Forest Ecology and Management, vol. 256, no. 6, pp. 1239-1252, Settember 2008.

[6] Chair Canadian Interagency Forest Fire Centre. (2002). Glossary of Forest Fire Management Terms. [Online]. Available: http://www.env.gov.bc.ca/esd/fire_mgmt_gloss_2002.pdf

[7] C. C. Hardy and C. E. Hardy. (2007). Fire danger rating in the United States of America: an evolution since 1916. International Journal of Wildland Fire. [Online]. 16. pp. 217-231. Available: http://www.treesearch.fs.fed.us/pubs/27702

[8] R. C. Rothermel. (1972). A Mathematical Model for Predicting Fire Spread in Wildland Fuels. [Online]. p. 42. Available: http://www.treesearch.fs.fed.us/pubs/32533

[9] J. H. Scott and R. E. Burgan, Standard Fire Behaviour Fuel Models: A comprehensive Set for Use with Rothermel's Surface Fire Spread Model, pp. 1-74, 2005.

[10] Foresty Canada Fire Danger Group. (1992). Development and Structure of the Canadian Forest Fire Behavior Prediction System. Ottawa: Foresty Canada Science and Sustainable Develompent Directorate. [Online]. pp. 1-63. Available: http://cfs.nrcan.gc.ca/pubwarehouse/pdfs/10068.pdf

[11] I. R. Noble, G. A. V. Bary, and A. M. Gill, "McArthur fire-danger meters expressed as equations," Australian Journal of Ecology, vol. 5, pp. 201-203, 1980

[12] A. J. Dowdy, G. A. Mills, K. Finkele, and W. de Goot. (2009) Australian Fire Weather as Represented by the McArthur Forest Fire Danger Index and the Canadian Forest Fire Weather Index. CAWCR. [Online].

Available: http://www.cawcr.gov.au/publications/technicalreports/CTR_010.pdf

[13] A. Lanorte and R. Lasaponara. (Febbruary 2008). Fuel type characterization based on coarse resolution MODIS satellite data iForest - Biogeosciences and Forestry. [Online]. 1. pp. 60-64. Available: http://www.sisef.it/iforest/contents/?id=ifor0451-0010060 
[14] M. Bonazountas, A. Astyakopoulos, M. Martino, F. Vinci, and V. Gagliardi. (2014). ArcFuel: Mediterranean Fuel Maps Geodatabase for Wildland \&Forest Fire Safety: "Final Report". Europian Commision. [Online]. Available: http://www.arcfuel.eu/index.php/en/documents.html

[15] WWF. (2001). An Analysis of Key Issues that Underlie Forest Fires and Shape Subsequent Fire Management Strategies in 12 Countries in the Mediterranean Basin. [Online]. Available: http://ec.europa.eu/environment/forests/pdf/meeting140504_wwfseco ndocument.pdf

[16] F. Giorgi and P.Lionello, "Climate change projections for the Mediterranean region," Global and Planetary Change, vol. 63, no. 2-3, pp. 90-104, Setember 2008.

[17] P. Lionello, P. Malanotte-Rizoli et al., "The Mediterranean climate: An overview of the main characteristics and issues," in Mediterranean Climate Variability, P. Lionello, P. Malanotte-Rizzoli and R. Boscolo, Ed., Amsterdam: Elsevier, pp. 1-18, 2006.

[18] Wikipedia. (2015). Marmediterraneo. [Online]. Available: http://it.wikipedia.org/wiki/Mar_Mediterraneo

[19] C. Giordano, "Mediterranean region," The Brill Dictionary of Religion, vol. 3, pp. 1201-1209, 2006.

[20] J. R. Hobbs, D. M. Richardson, and G. W. Davis, "Mediterranean-typer ecosystems: Opportunities and constrains for studing the function of biodiversity," in Mediterranean-Typer Ecosystems. The Function of Biodiversity, G. W. Davis and D. M. Richardson, Ed., Berlin Heidelberg: Springer-Verlag, ch. 1, pp. 1-42, 1995.

[21] J. Blondel and J. Aronson, "Biodiversity and ecosystem function in the Mediterranean basin: Human and non-human determinants," in Mediterranean-Typer Ecosystems. The Function of Biodiversity, G.W. Davis and D. M. Richardson, Ed., Berlin Heidelberg: Springer-Verlag, ch. 2, pp. 43-105, 1995.

[22] WWF. Forest Fires in the Mediterranean: A Burning Issue. [Online]. Available:

http://www.google.it/url?sa=t\&rct=j\&q=\&esrc=s\&source=web\&cd=2 \&ved=0CCkQFjAB\&url=http\%3A\%2F\%2Fwww.panda.org\%2Fdow nloads\%2Fforestfires2003factfile.doc\&ei=FwpvVYmECoWrsgGXv YHwCQ\&usg=AFQjCNHDFuwB1_3hvu_Z6Bwu51D9zyiHIQ\&sig2 =s198XF5Q7aZlyJUvkP_GvQ
[23] Agenzia Nazionale per la Protezione dell'Ambiente, "Presentazione della regione biogeografica: Estensione, clima, rilievi e paesaggi," $L a$ Biodiversità Nella Regione Biogeografica Mediterranea, Roma: ANPA, ch. 1, pp. 1-9, 2001.

[24] S. Pignatti, "Plant geographical and morphological evidences in the evolution of the Mediterranean flora (with particular reference to the Italian representatives)," Webbia: Journal of Plant Taxonomy and Geography, vol. 34, no. 1, pp. 243-255, 1979.

[25] R. E. Keane, R. Burgan, and J. V. Wagtendonk, "Mapping wild land fuels for fire management across multiple scales: Integrating remote sensing," GIS and biophysical modeling," International Journal of Wildland Fire, vol. 10, pp. 301-319, 2001.

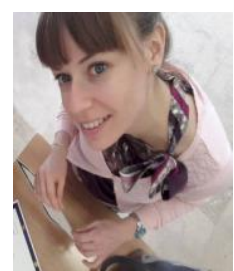

Isida Duka was born in Albania in 1986. She graduated in 2011 in Territorial, Environmental and City Planning at 'Sapienza' University of Rome, Italy. In 2014 she obtained with laude, her M.Sc in Geo-G.S.T. at University of 'Tor Vergata', Rome. From 2008 to 2013 she engaged in numerous projects in the field of urban planning, design, coaching, and teaching, in Italy and Albania. She is the author of two book chapters (in Italian), three (in Albanian) and one paper (in English). From 2014 she is following her $\mathrm{PhD}$ in computer science control and geo-information at University of 'Tor Vergata', Rome, Italy.

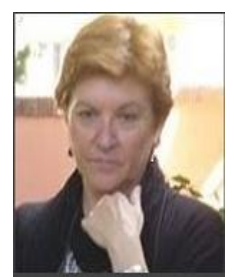

Maria Ioannilli is a research professor in Technical Urban Planning at Tor Vergata University of Rome. She also is a professor in postgraduate courses in "geographical information systems applied to town and country planning", in "GIS and remote sensing", in "planning and management instruments" and in PhD course "geo-information". She is the director of the master in "geoinformation and geographic information systems supporting the territory sustainable management and the spatial safety" (University "Tor Vergata" of Rome). She is the author of about than 60 papers on national and international magazines and conferences in the research fields and of one book (in Italian) on GIS. 